\title{
Android Virtual Machine (VM) Setup on Linux
}

\author{
by Ken F Yu
}

ARL-TN-0651

December 2014 


\section{NOTICES}

\section{Disclaimers}

The findings in this report are not to be construed as an official Department of the Army position unless so designated by other authorized documents.

Citation of manufacturer's or trade names does not constitute an official endorsement or approval of the use thereof.

Destroy this report when it is no longer needed. Do not return it to the originator. 


\title{
Army Research Laboratory
}

Adelphi, MD 20783-1138

\section{Android Virtual Machine (VM) Setup on Linux}

\author{
Ken F Yu \\ Computational and Information Sciences Directorate, ARL
}




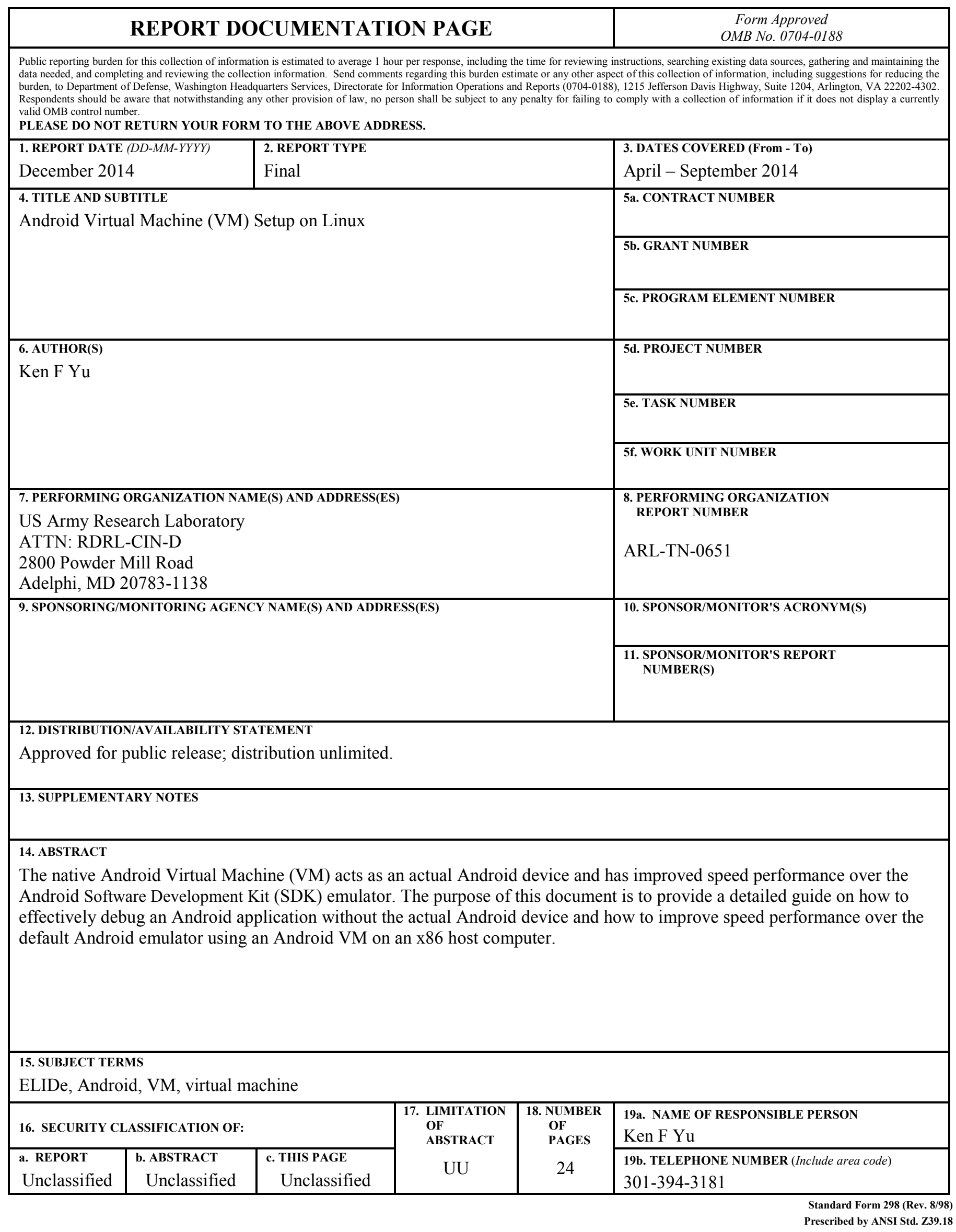




\section{Contents}

List of Figures $\quad$ iv

$\begin{array}{ll}\text { 1. Software Requirements } & 1\end{array}$

2. Android Setup on VirtualBox 1

$\begin{array}{lr}\text { 3. Conclusions } & 14\end{array}$

4. References $\quad 15$

List of Symbols, Abbreviations, and Acronyms 16

$\begin{array}{ll}\text { Distribution List } & 17\end{array}$ 


\section{List of Figures}

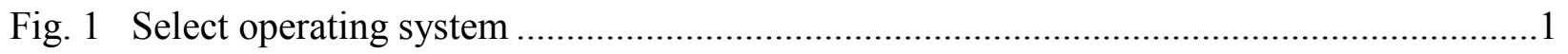

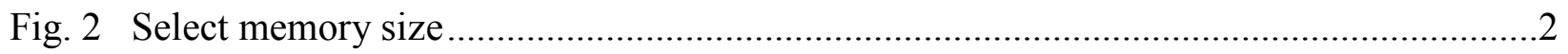

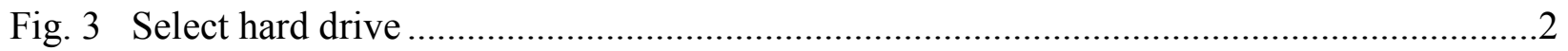

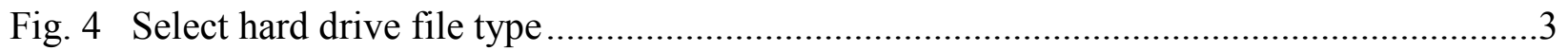

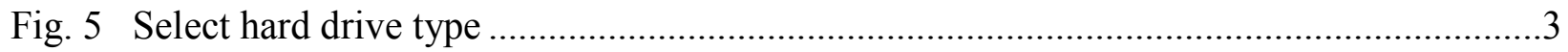

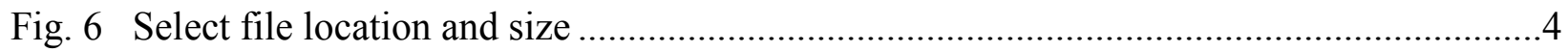

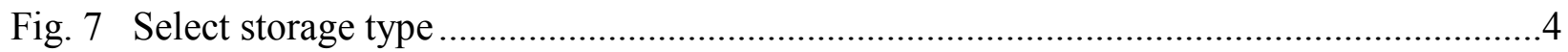

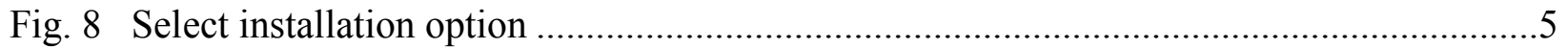

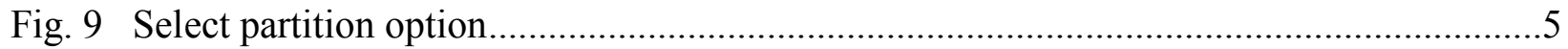

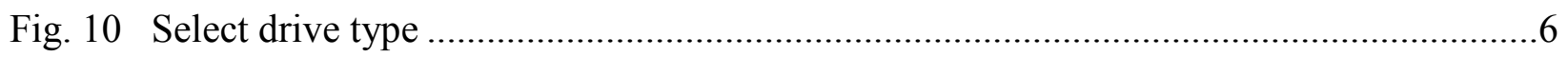

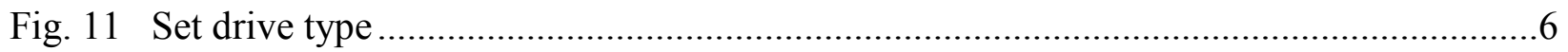

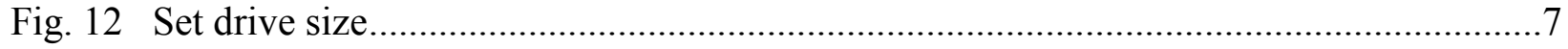

Fig. 13 Select bootable drive ..................................................................................

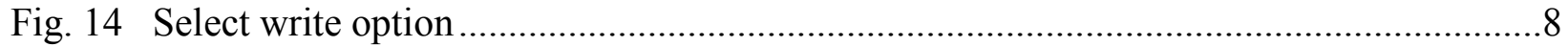

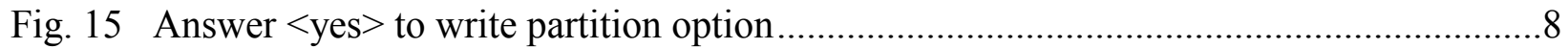

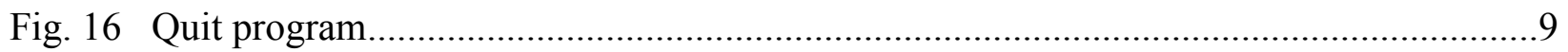

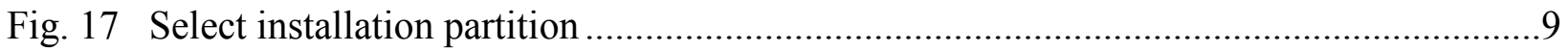

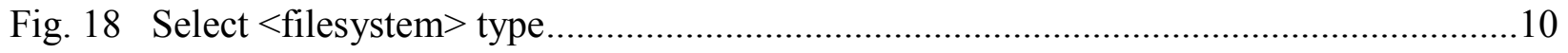

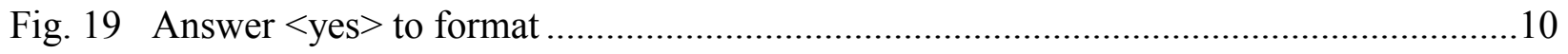

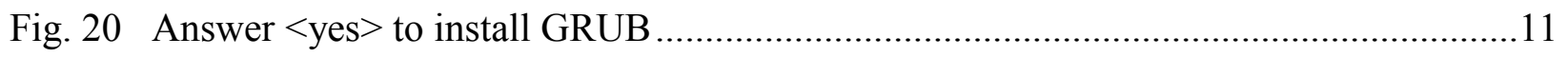

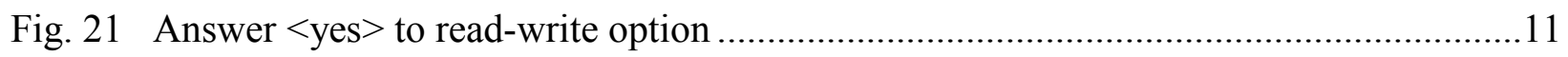

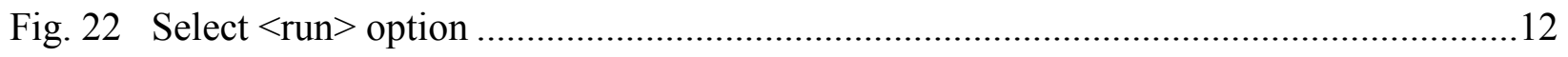

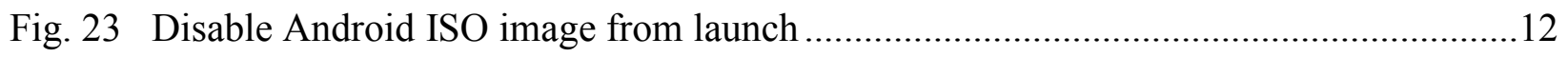

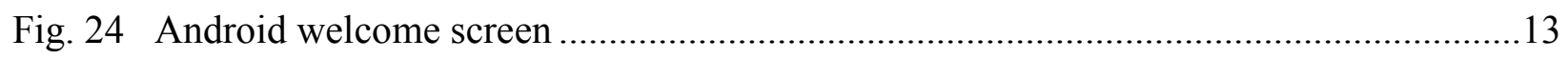


INTENTIONALLY LEFT BLANK. 


\section{Software Requirements}

The following software packages are required:

1) VirtualBox ${ }^{1}$ can be used as a Virtual Machine (VM) to emulate Android natively.

2) Android- $x 86^{2}$ can be installed on any Intel-processor-based VM.

3) The Software Development Kit (SDK) $)^{3}$ can be used to interact with the Android VM, but it is not necessary to install it on an Android VM.

\section{Android Setup on VirtualBox}

Before the Android VM can be used, the VirtualBox from Oracle must be installed. After VirtualBox is installed, type the command $<$ virtualbox $>$ from the console to start the VirtualBox application. Then, create an Android VM on Linux using the following procedures:

1) Click the $<$ New $>$ button VirtualBox. It will bring up the VirualBox setup screen. Type the name of the VM (i.e., Android). Select the Type: Linux. Select a Linux version, such as $<$ Linux 2.6 $>$. Click $<$ Next $>$ (Fig. 1).

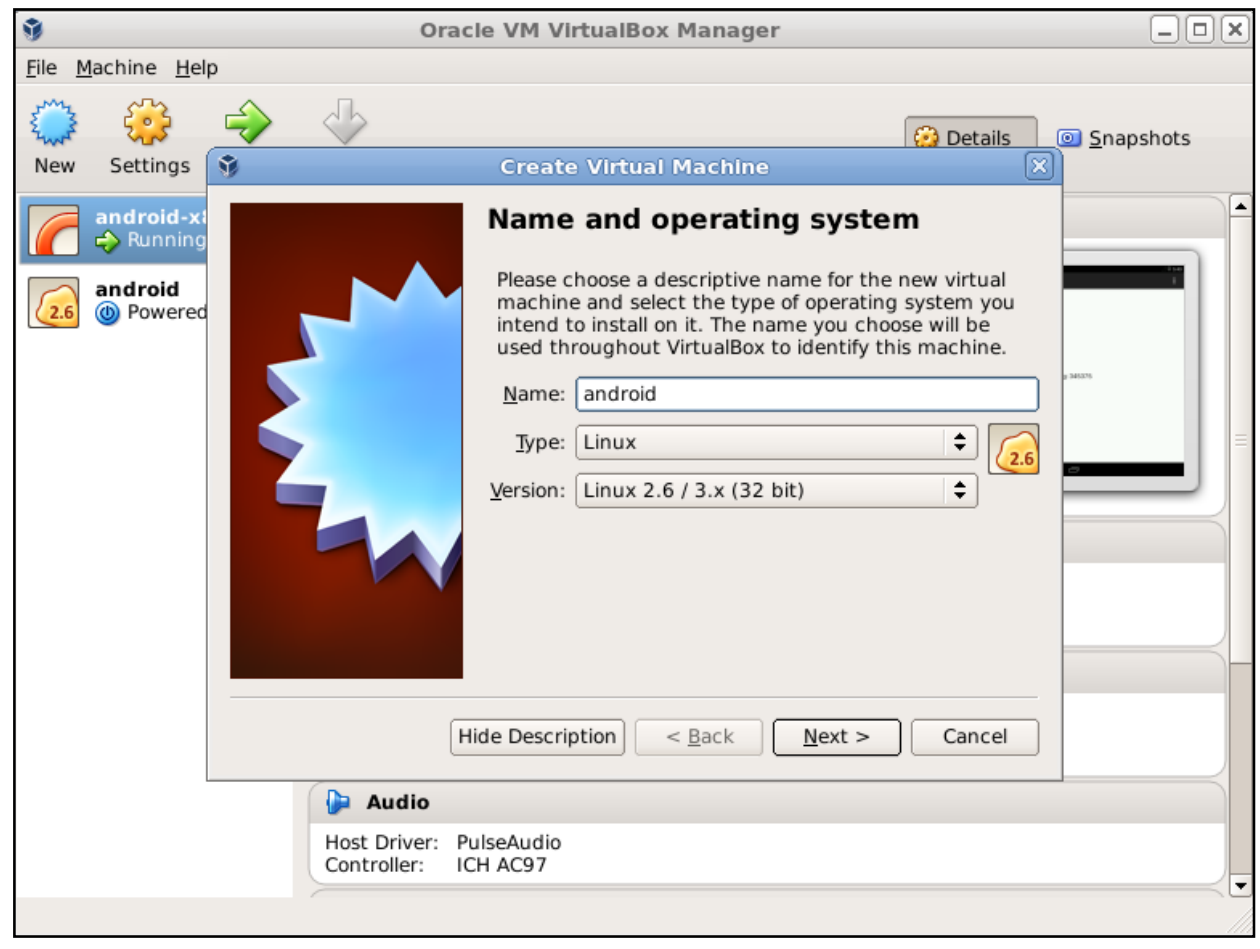

Fig. 1 Select operating system 
2) Pick the memory size, such as $1024 \mathrm{MB}$, click $<$ Next $>$ (Fig. 2).

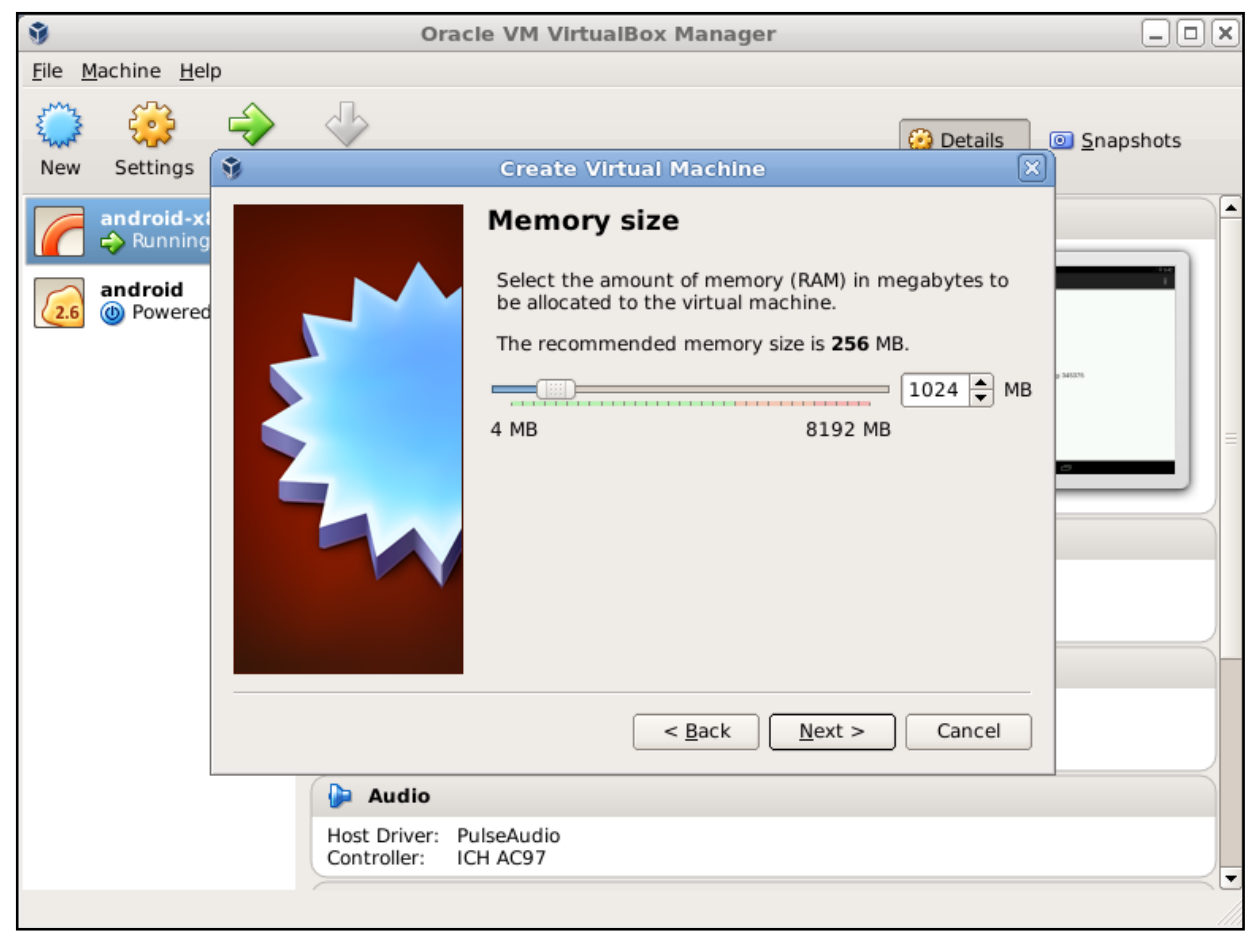

Fig. 2 Select memory size

3) Create a virtual drive, click $<$ Next $>$ (Fig. 3).

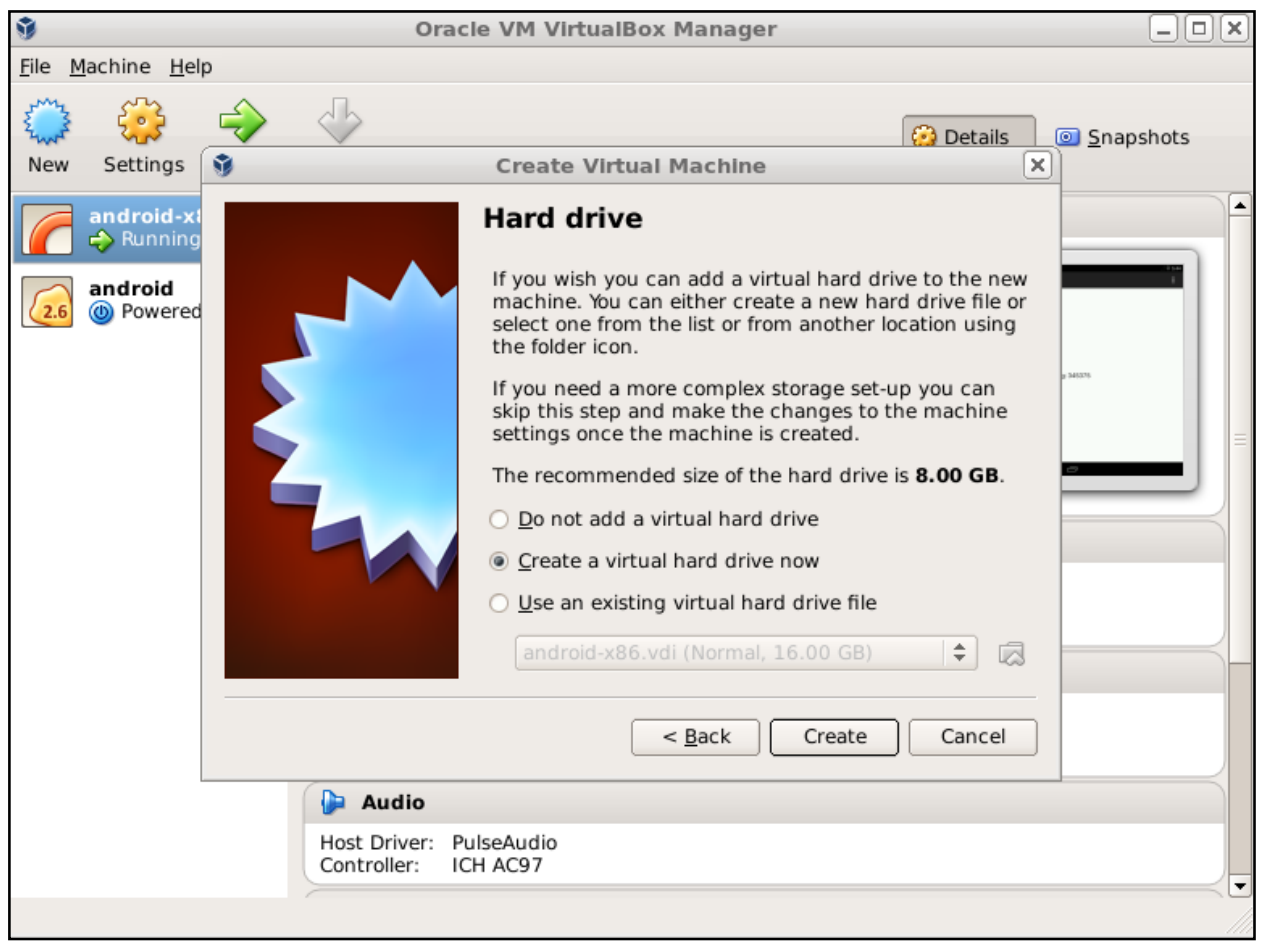

Fig. 3 Select hard drive 
4) Select $<$ VDI (Virtualbox Disk Image) $>$ disk image type (Fig. 4).

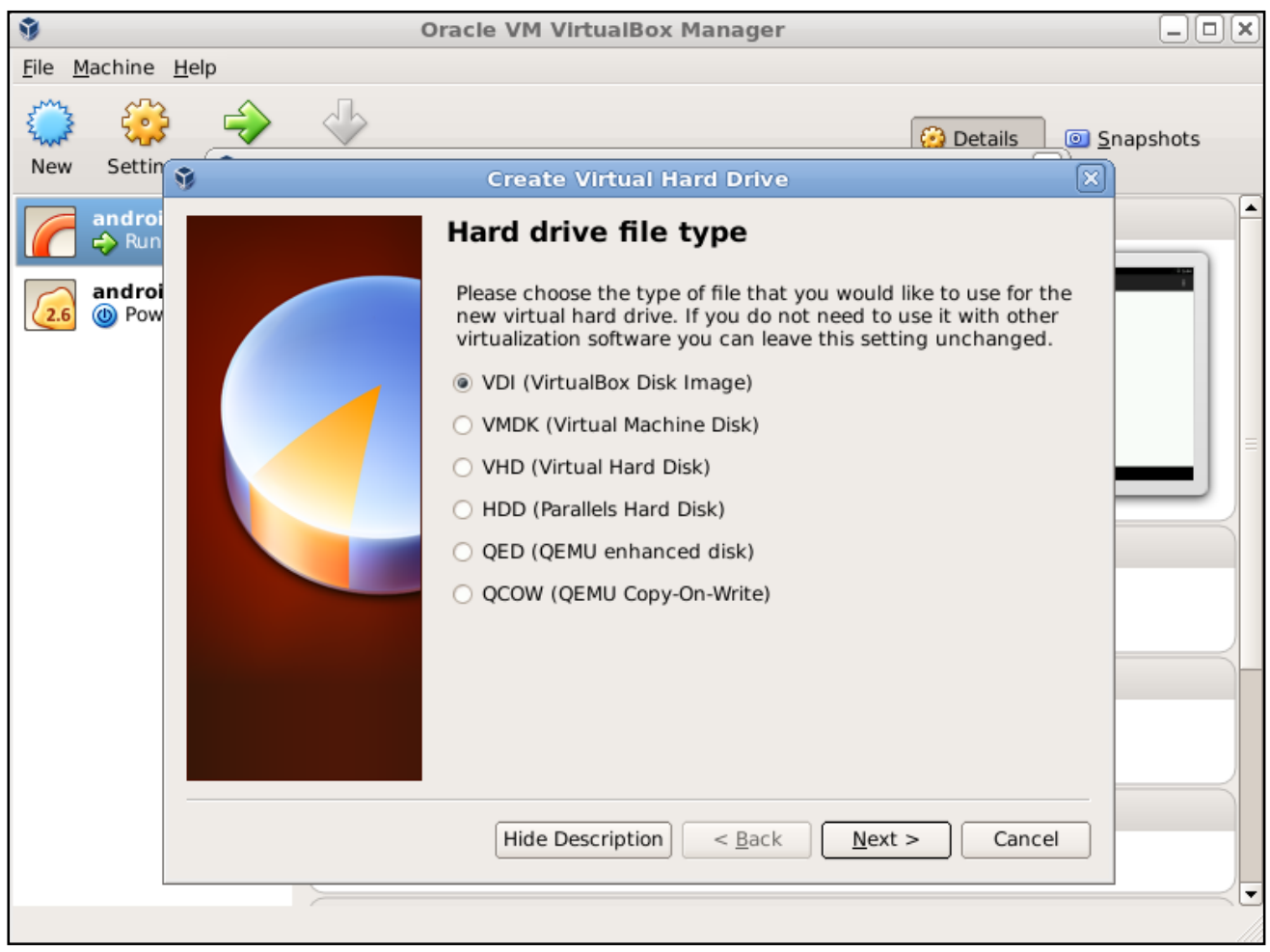

Fig. 4 Select hard drive file type

5) Select the storage type: "Dynamically allocated" is preferred (Fig. 5).

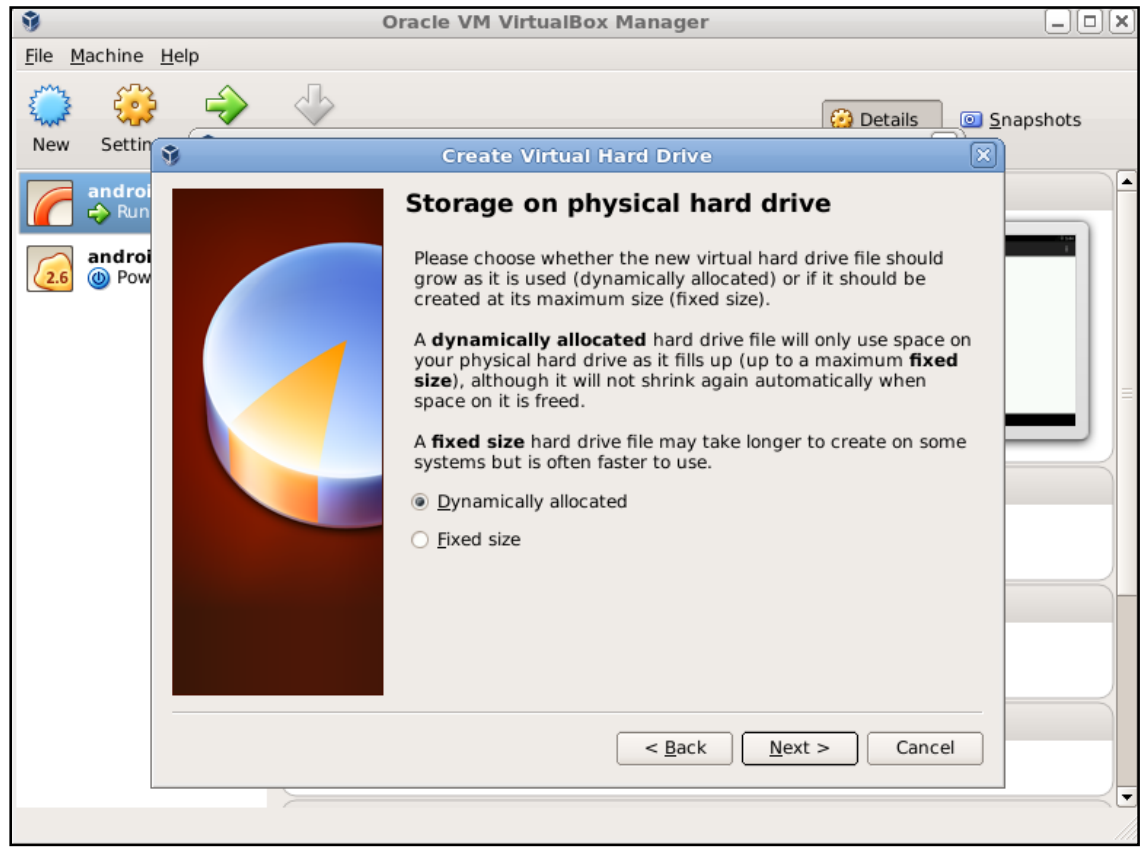

Fig. 5 Select hard drive type 
6) Next, pick the VM size (Fig. 6).

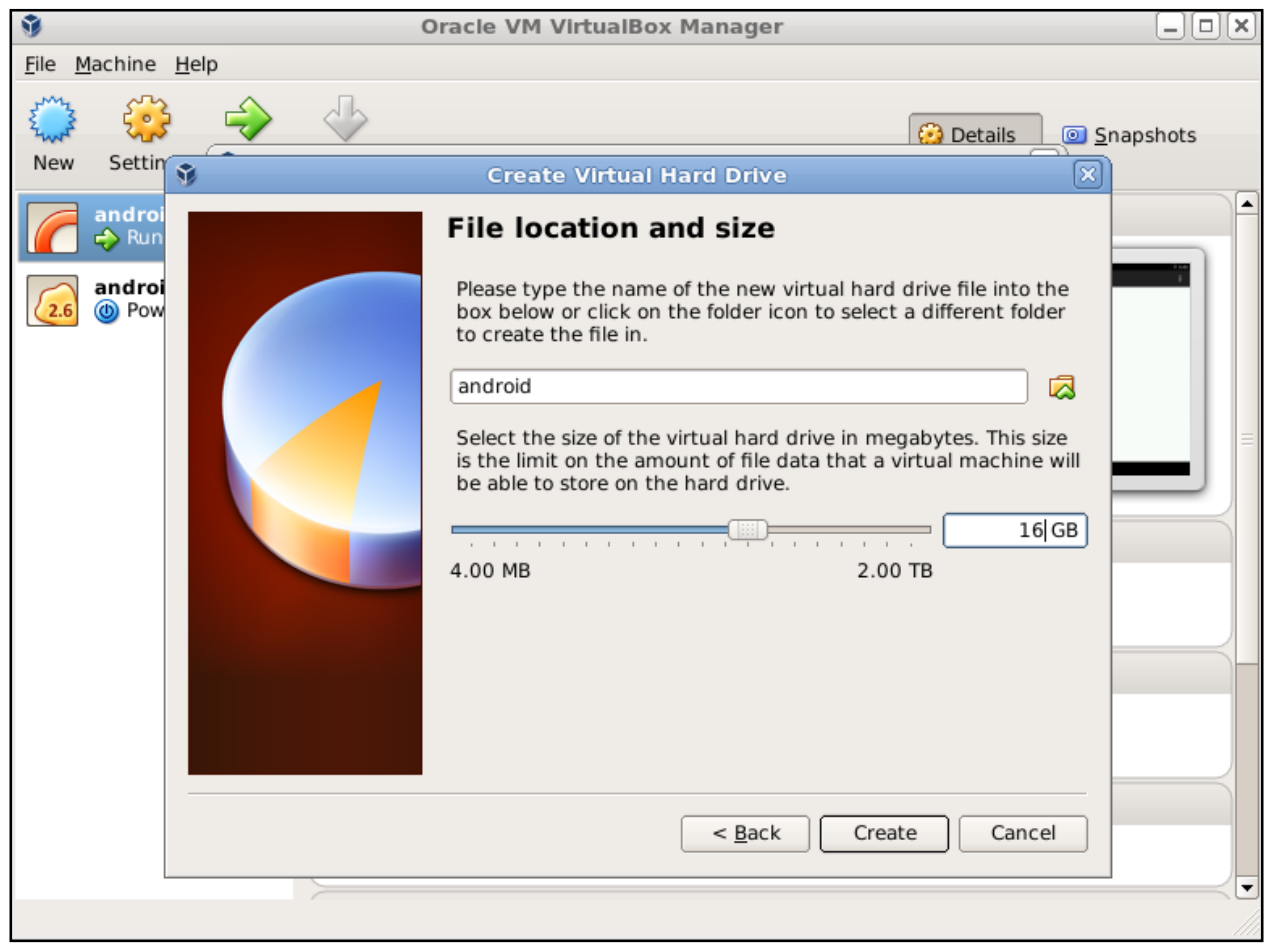

Fig. 6 Select file location and size

7) Go to the VirtualBox setting, select the storage type, and select the Android ISO image that was downloaded (Fig. 7).

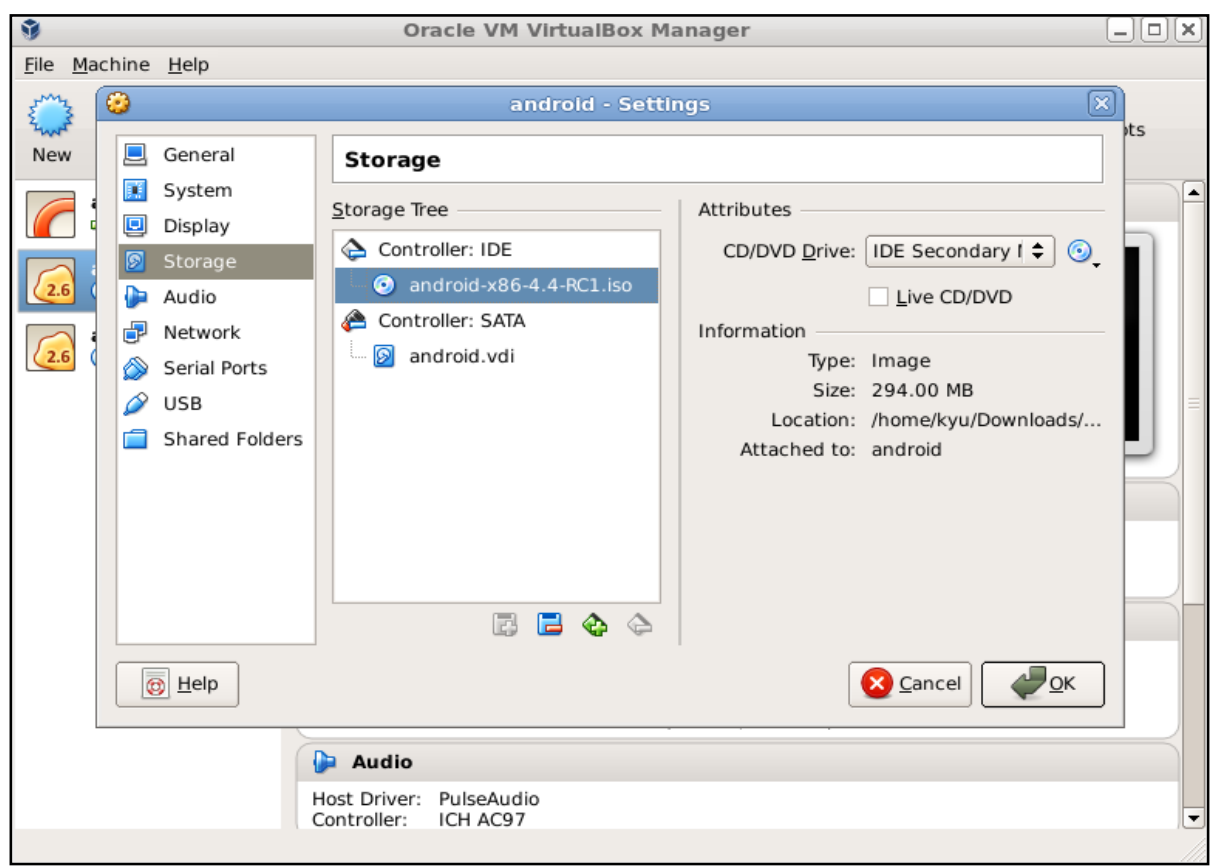

Fig. 7 Select storage type 
8) Run the VM that was just created with the Android ISO attached. Select the installation option (Fig. 8).

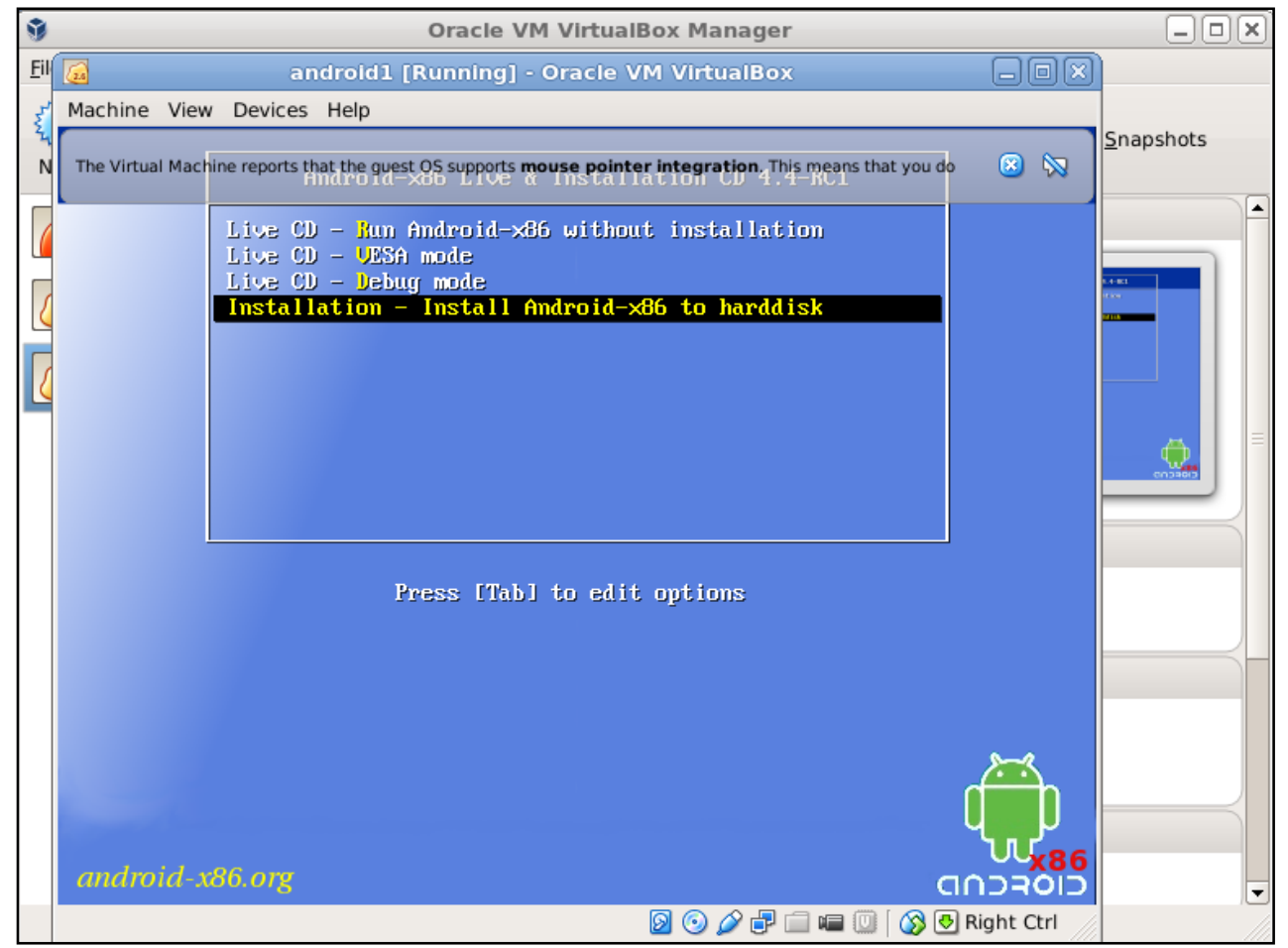

Fig. 8 Select installation option

9) Select the $<$ Create/Modify partitions $>$ option. Click $<$ OK $>$ (Fig. 9).

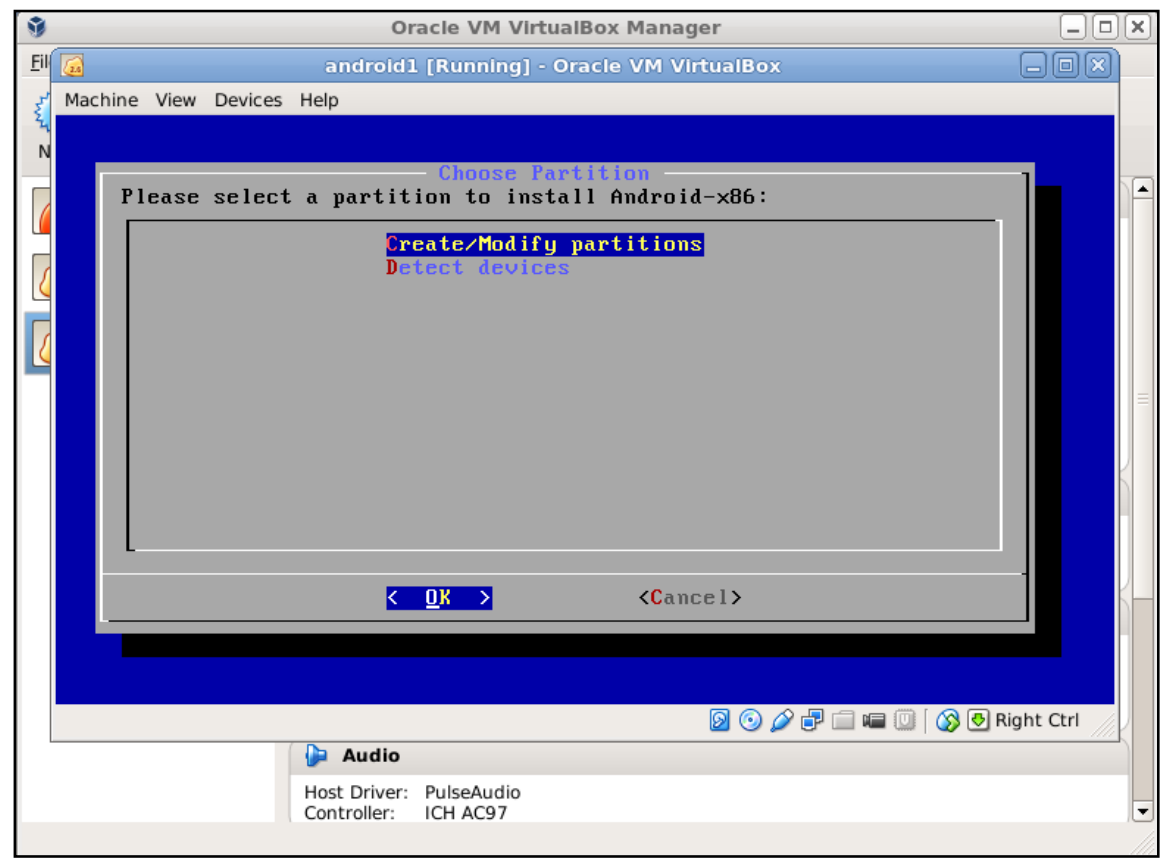

Fig. 9 Select partition option 
10) Click $<$ New $>$ for the Primary Drive (Fig. 10).

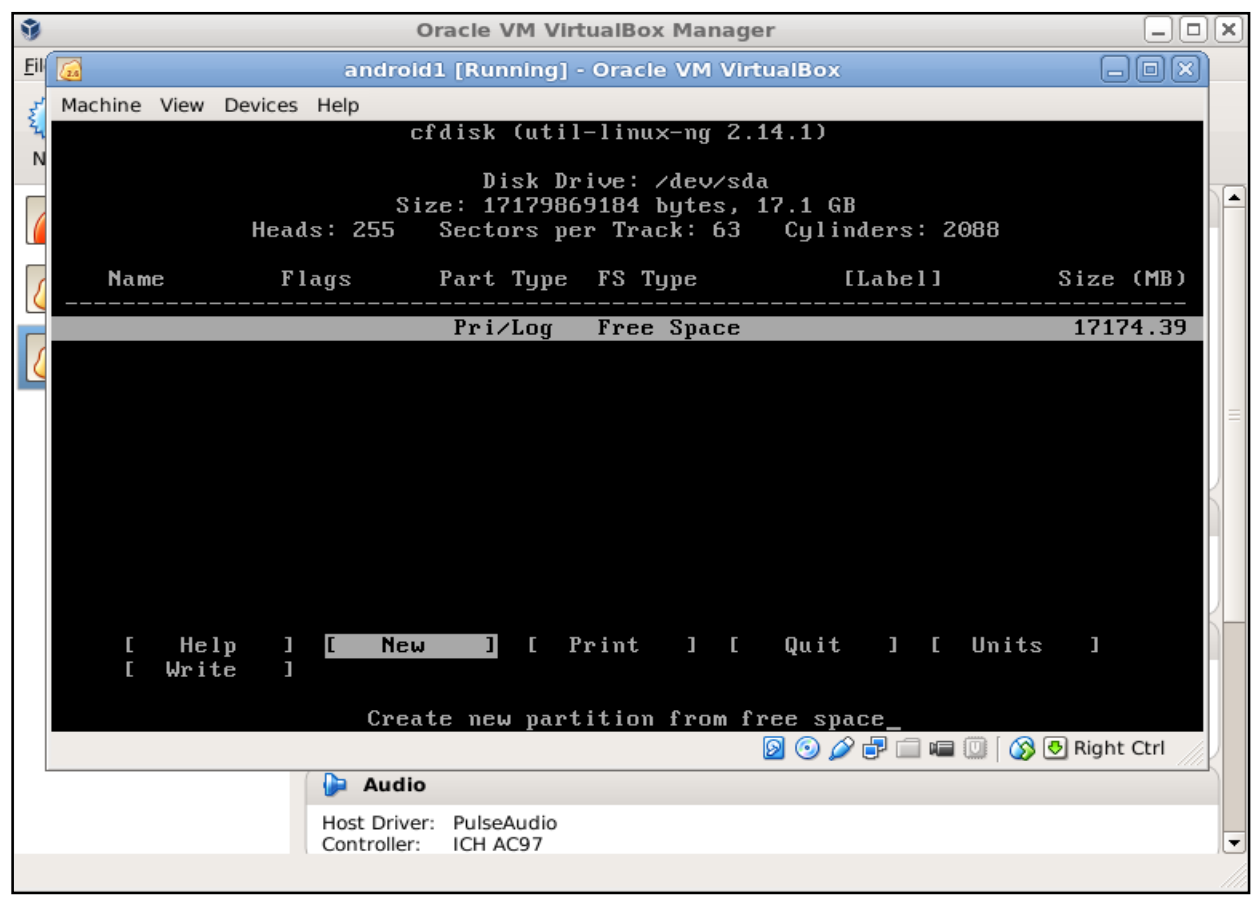

Fig. 10 Select drive type

11) Select the $<$ Primary $>$ option (Fig. 11).

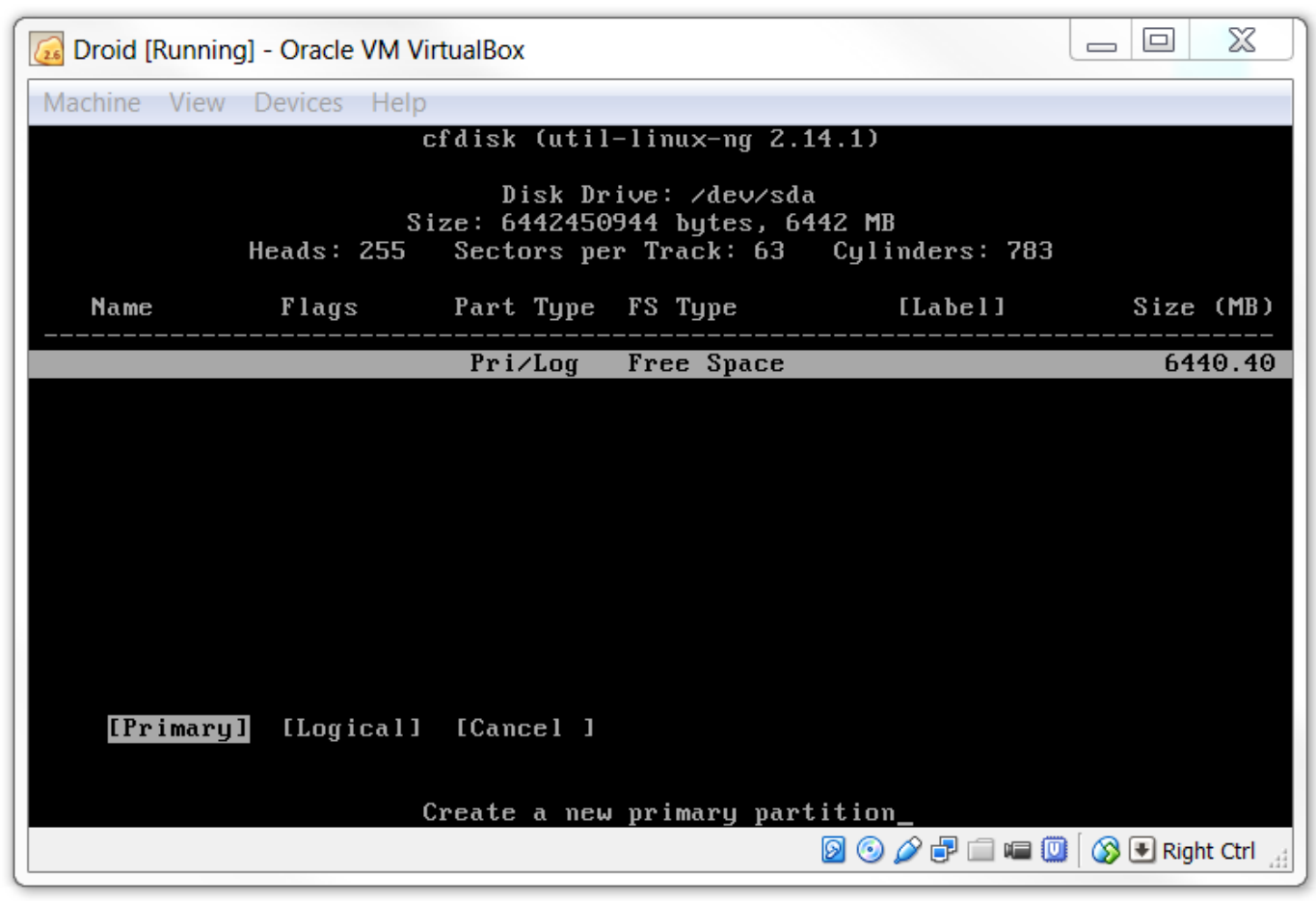

Fig. 11 Set drive type 
12) Set the size of the Primary Drive: $<$ default $>$ is sufficient (Fig. 12).

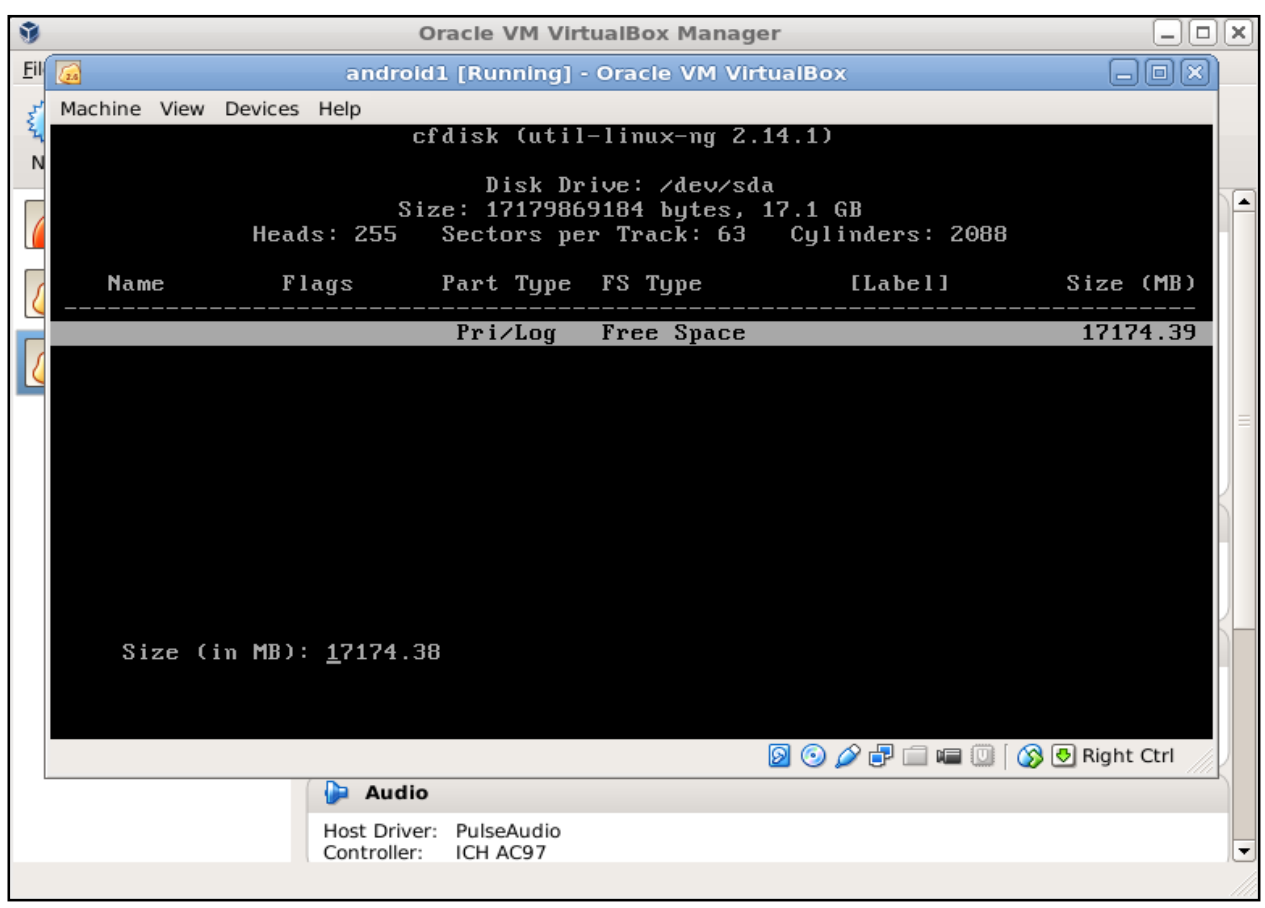

Fig. 12 Set drive size

13) Select a $<$ Bootable $>$ drive (Fig. 13).

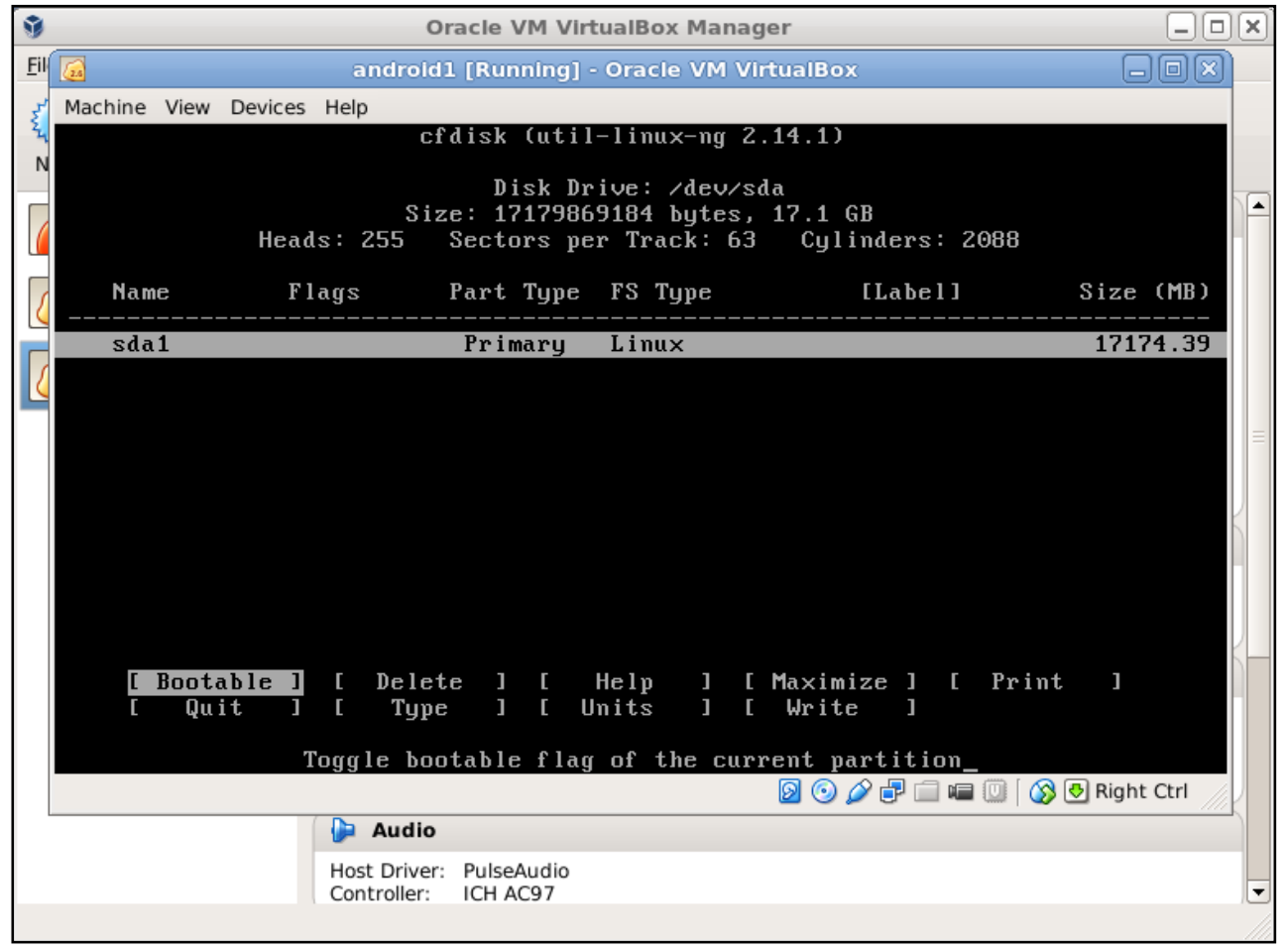

Fig. 13 Select bootable drive 
14) Select the $<$ Write $>$ option (Fig. 14).

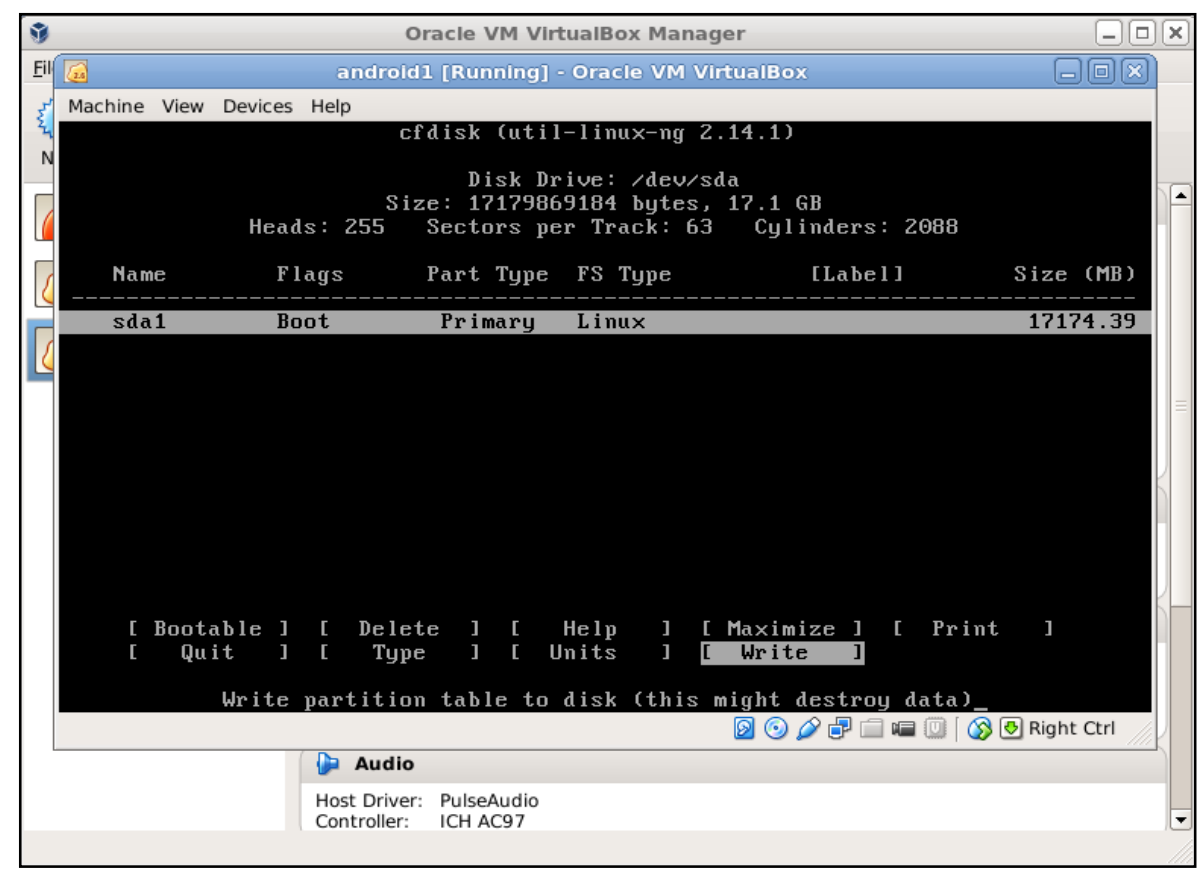

Fig. 14 Select write option

15) Answer $<$ yes $>$ to the $<$ write partition table to disk $>$ question (Fig. 15).

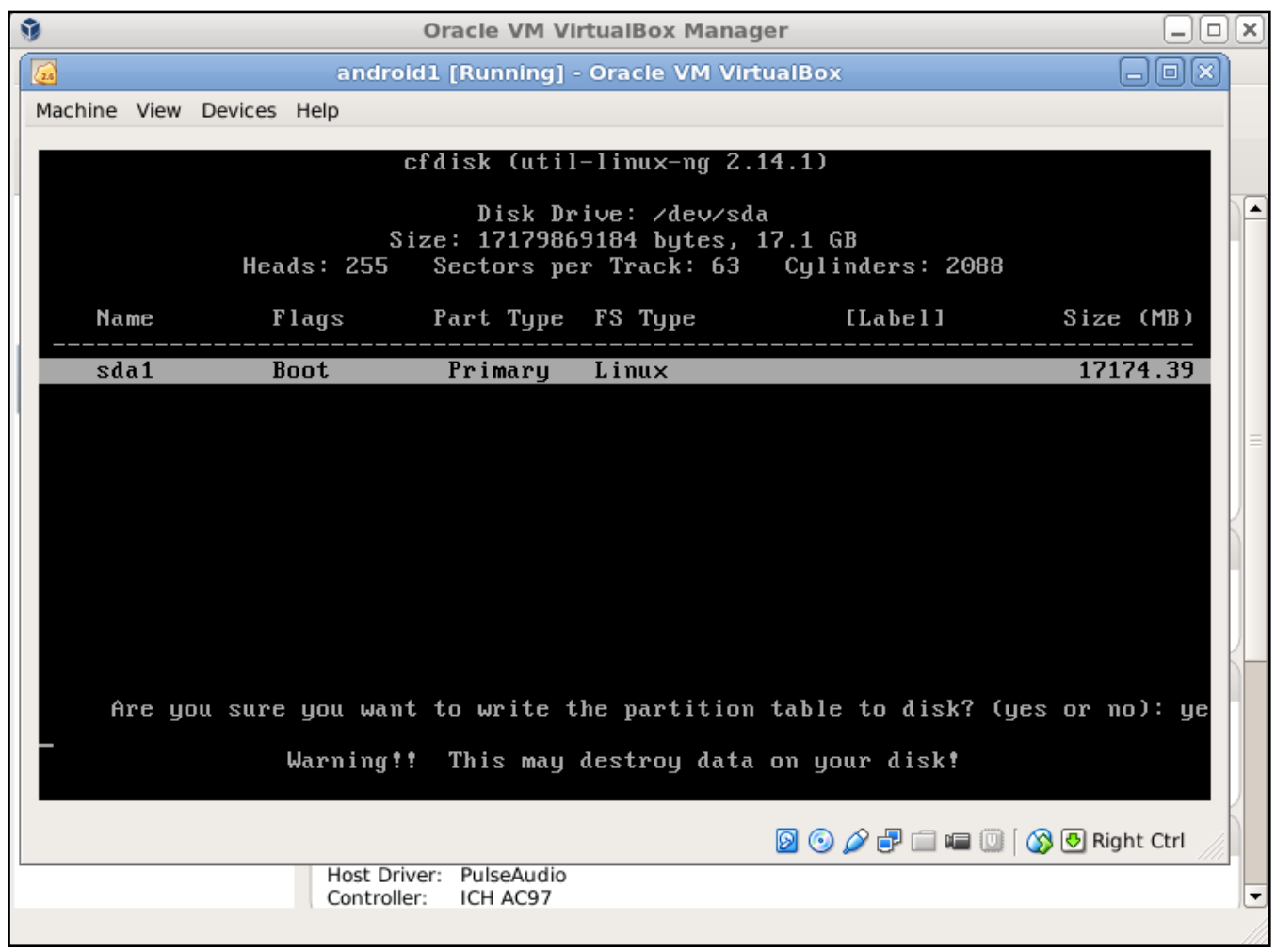

Fig. 15 Answer $<$ yes $>$ to write partition option 
16) After the $<$ write $>$ process is done, select $<$ Quit $>$ (Fig. 16).

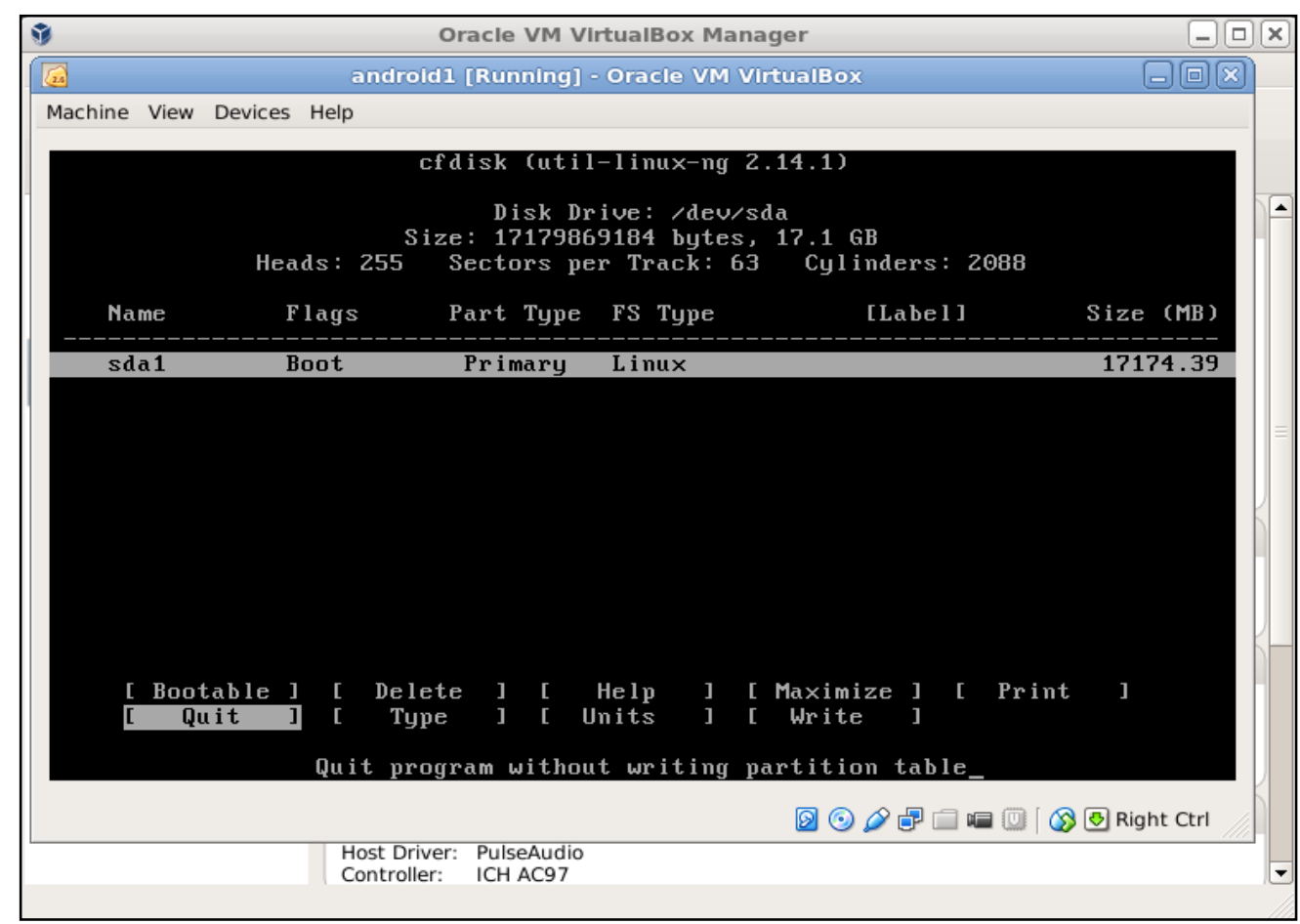

Fig. 16 Quit program

17) Select the $<$ sda1 Linux $>$ option. Click $<$ OK $>$ (Fig.17).

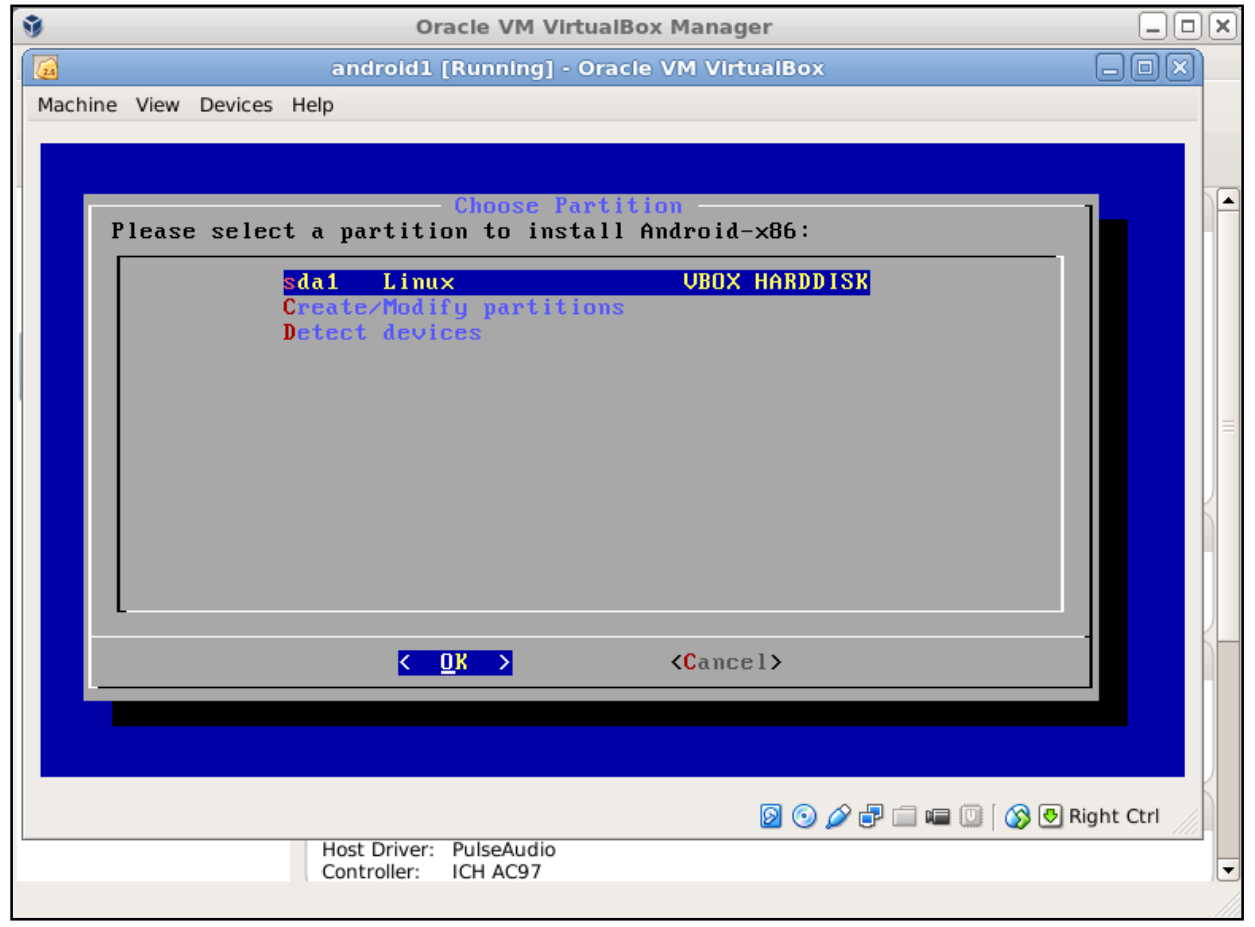

Fig. 17 Select installation partition 
18) Select the $<$ ext $3>$ option. Click $<\mathrm{OK}>$ (Fig. 18).

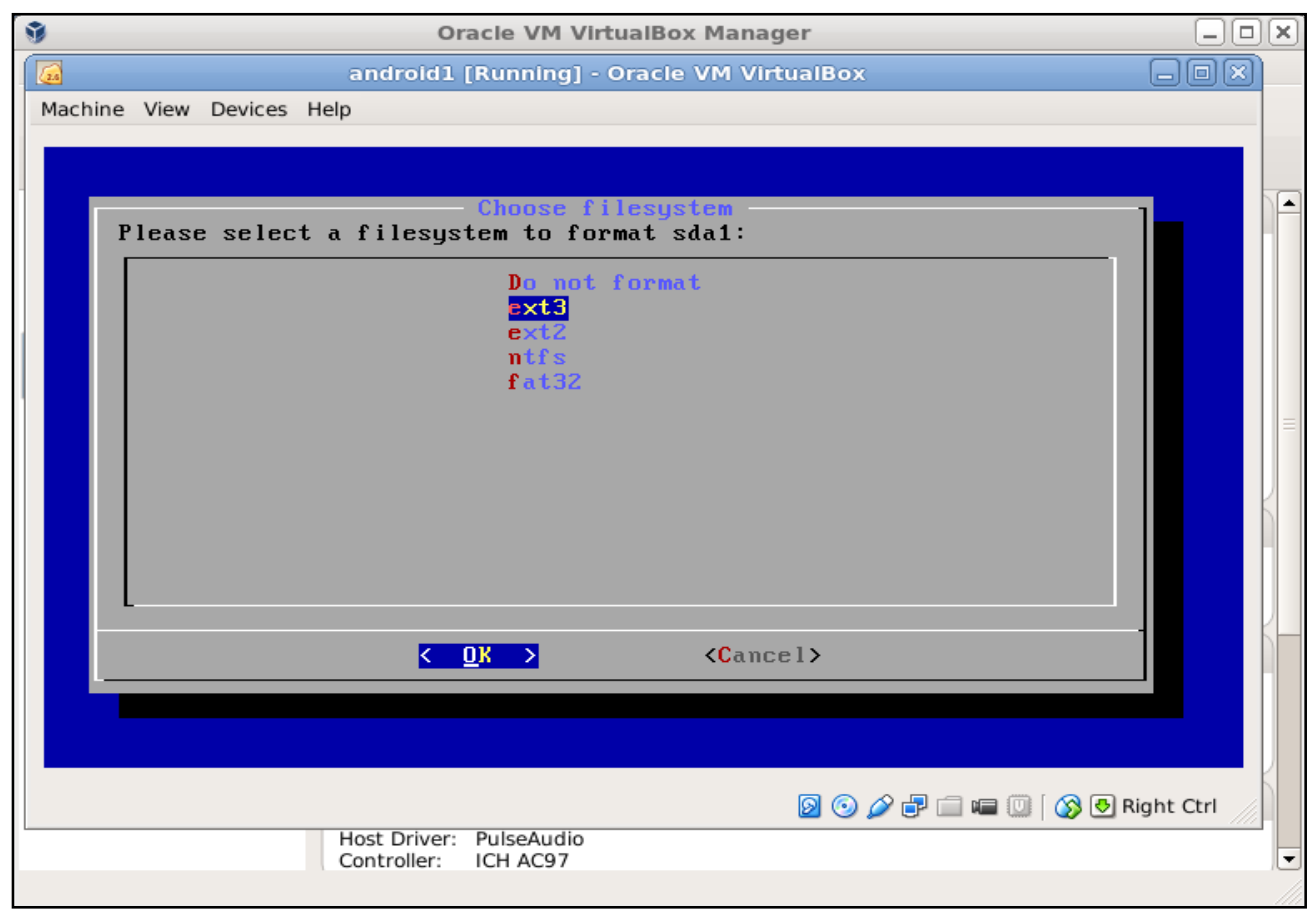

Fig. 18 Select $<$ filesystem $>$ type

19) Click $<$ yes $>$ in response to the formatting question (Fig. 19).

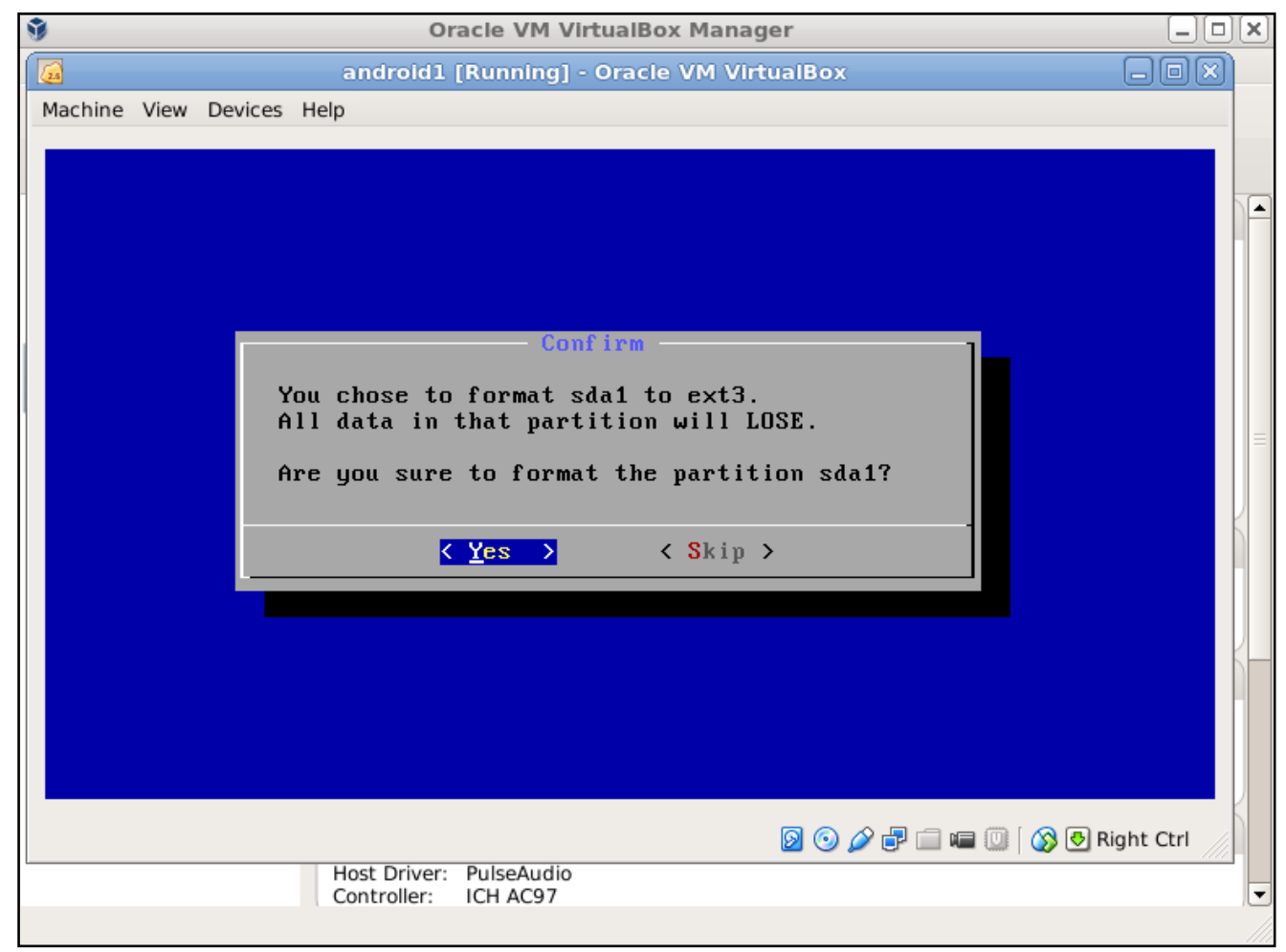

Fig. 19 Answer $<$ yes $>$ to format 
20) Install GNU GRand Unified Bootloader (GRUB) and click $<$ Yes $>$ (Fig. 20). GRUB provides more flexibility to boot different Linux installations during startup.

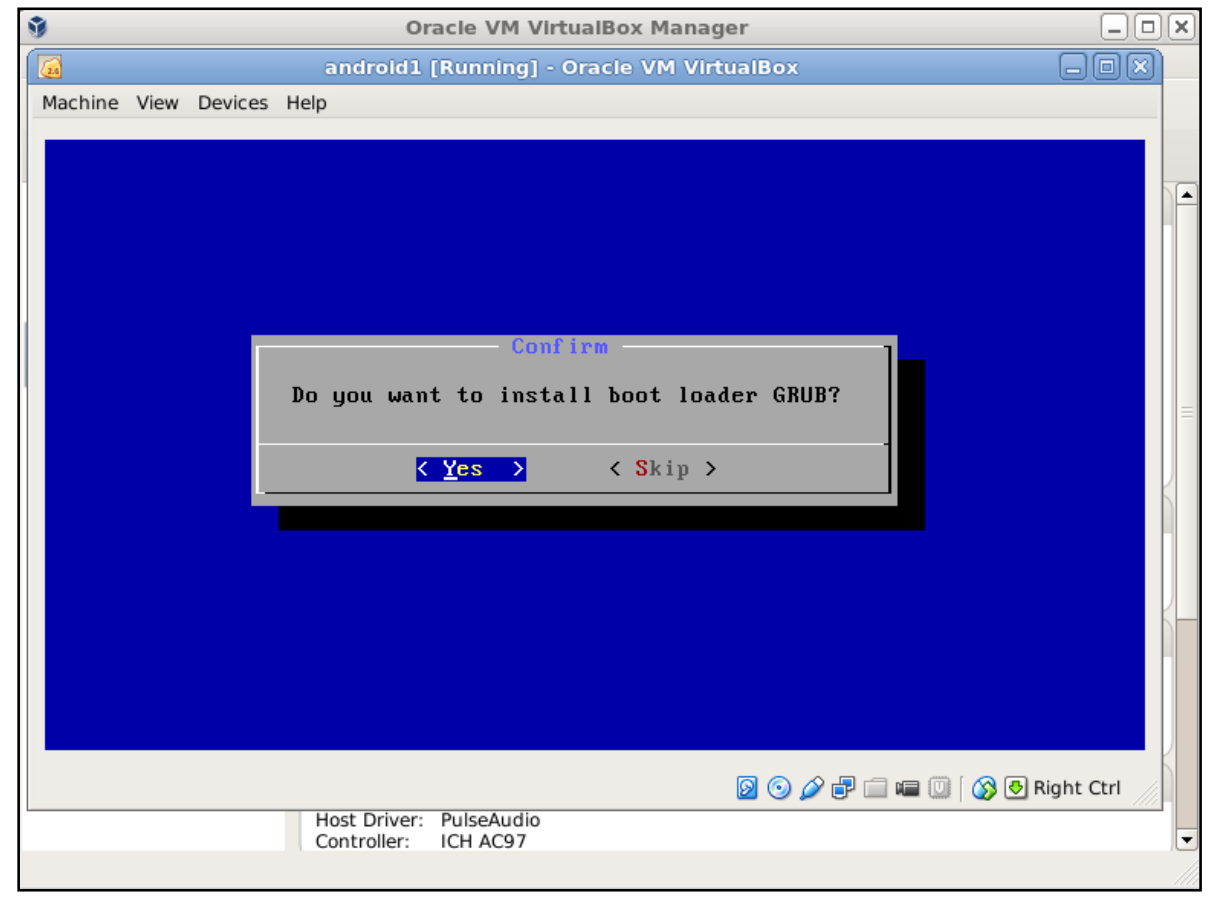

Fig. 20 Answer $<$ yes $>$ to install GRUB

21) Select $<$ Yes $>$ in response to the $<$ install/system directory as read-write $>$ question (Fig. 21).

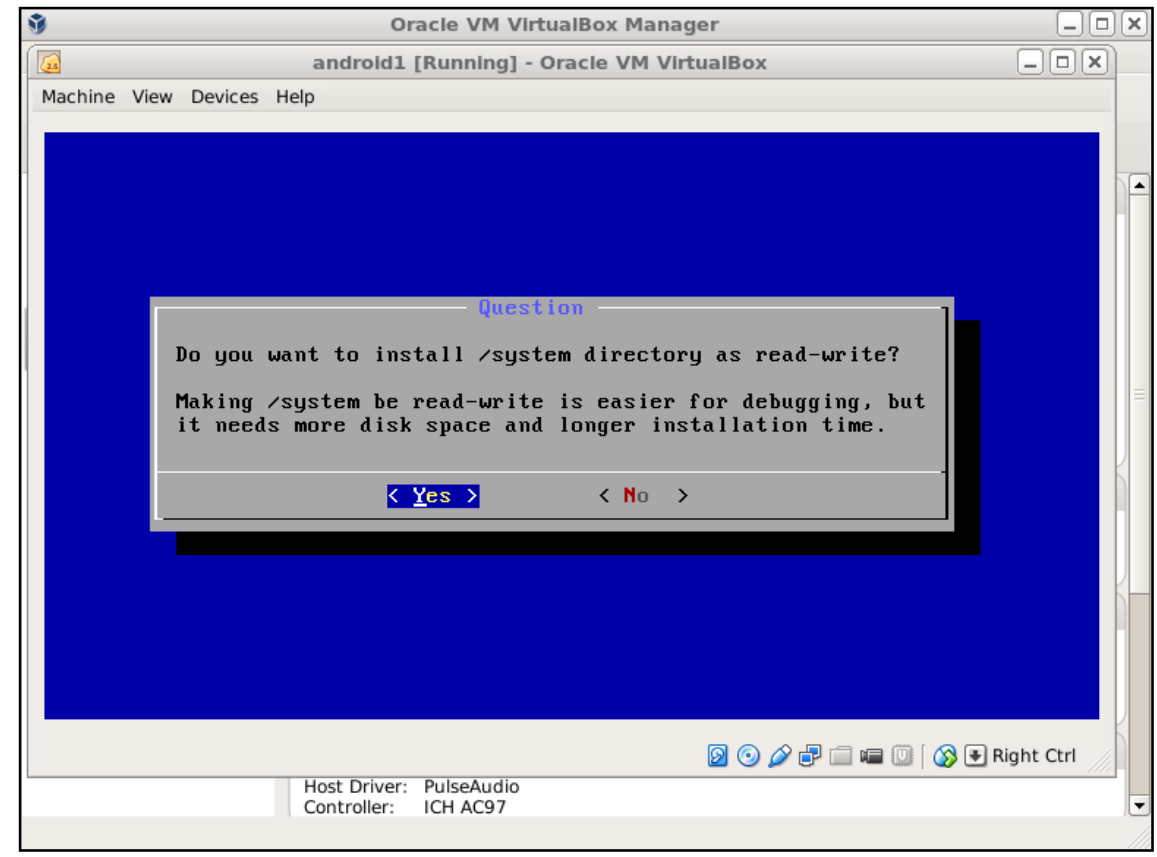

Fig. 21 Answer $<$ yes $>$ to read-write option 
22) Select the $<$ Run Android-x86 $>$ option (Fig. 22).

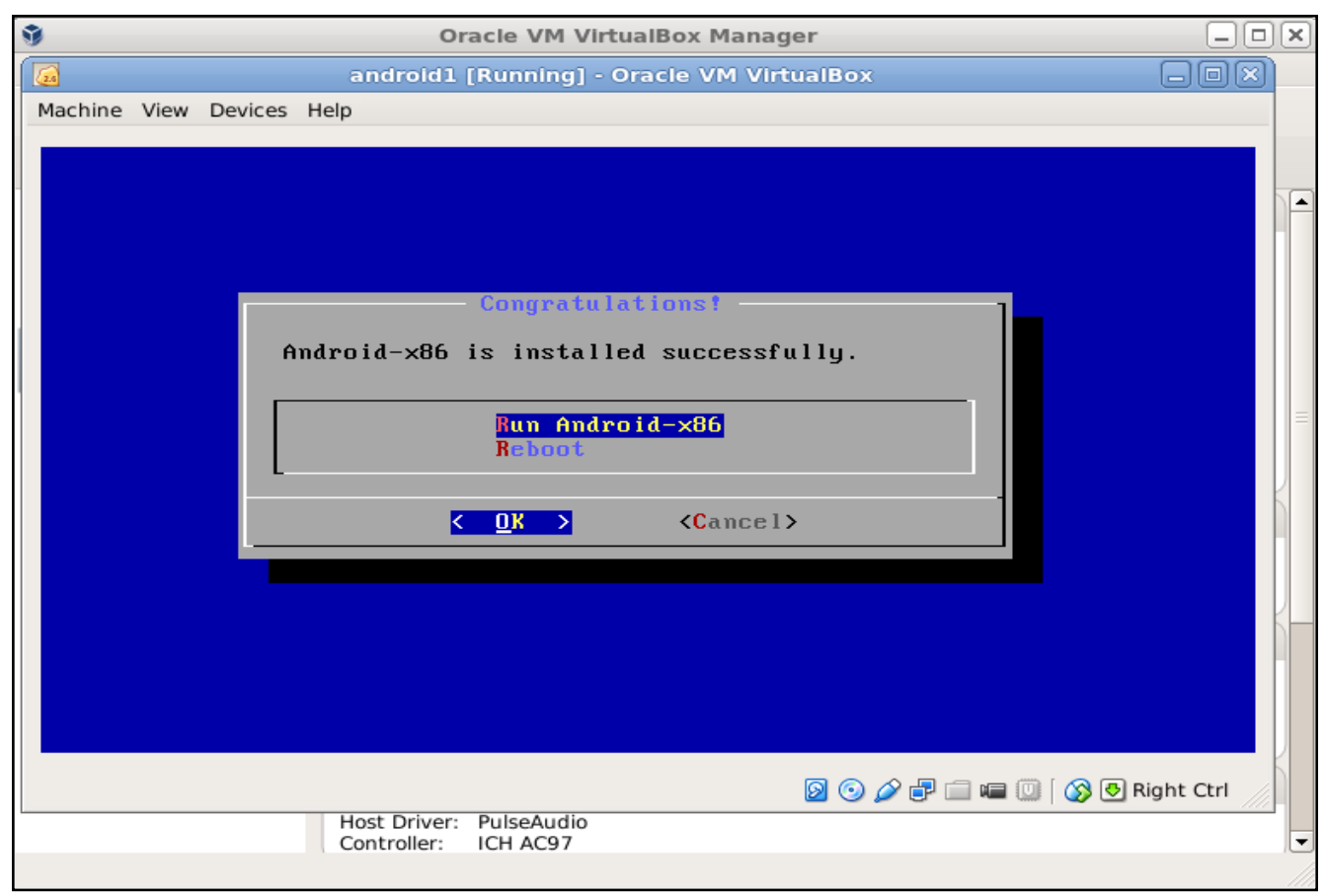

Fig. 22 Select $<$ run $>$ option

23) When Virtualbox is started, go to the $<$ Devices- $>$ CD/DVD Devices- $>$ Remove the disk from virtual drive $>$ option to remove the Android ISO (Fig. 23).

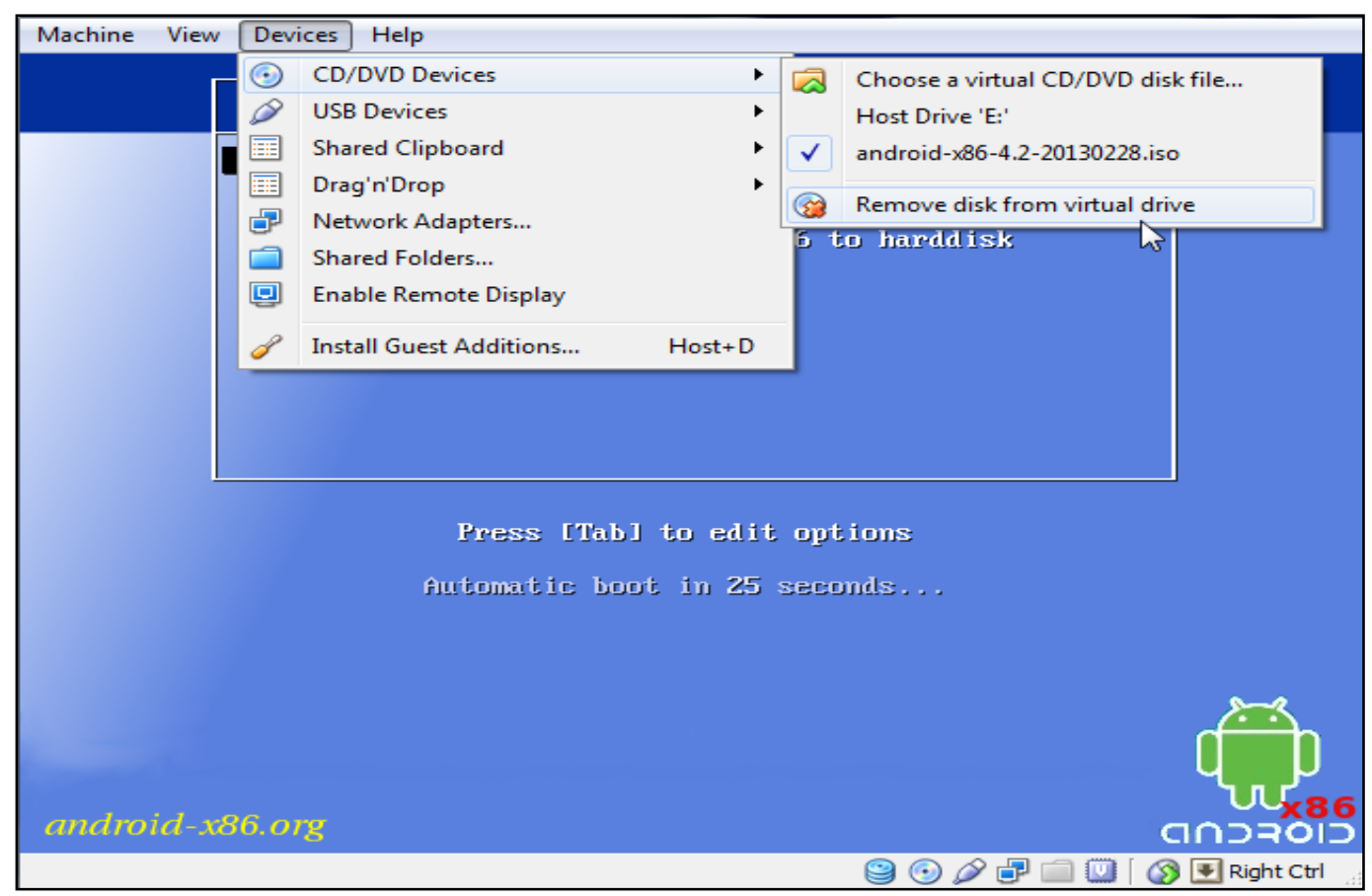

Fig. 23 Disable Android ISO image from launch 
24) After Android is booted, the Android Welcome screen appears (Fig. 24). This shows that the installation was successful on the VirtualBox. Next, go through the normal Android setup processes, and the Android device will now be activated for use.

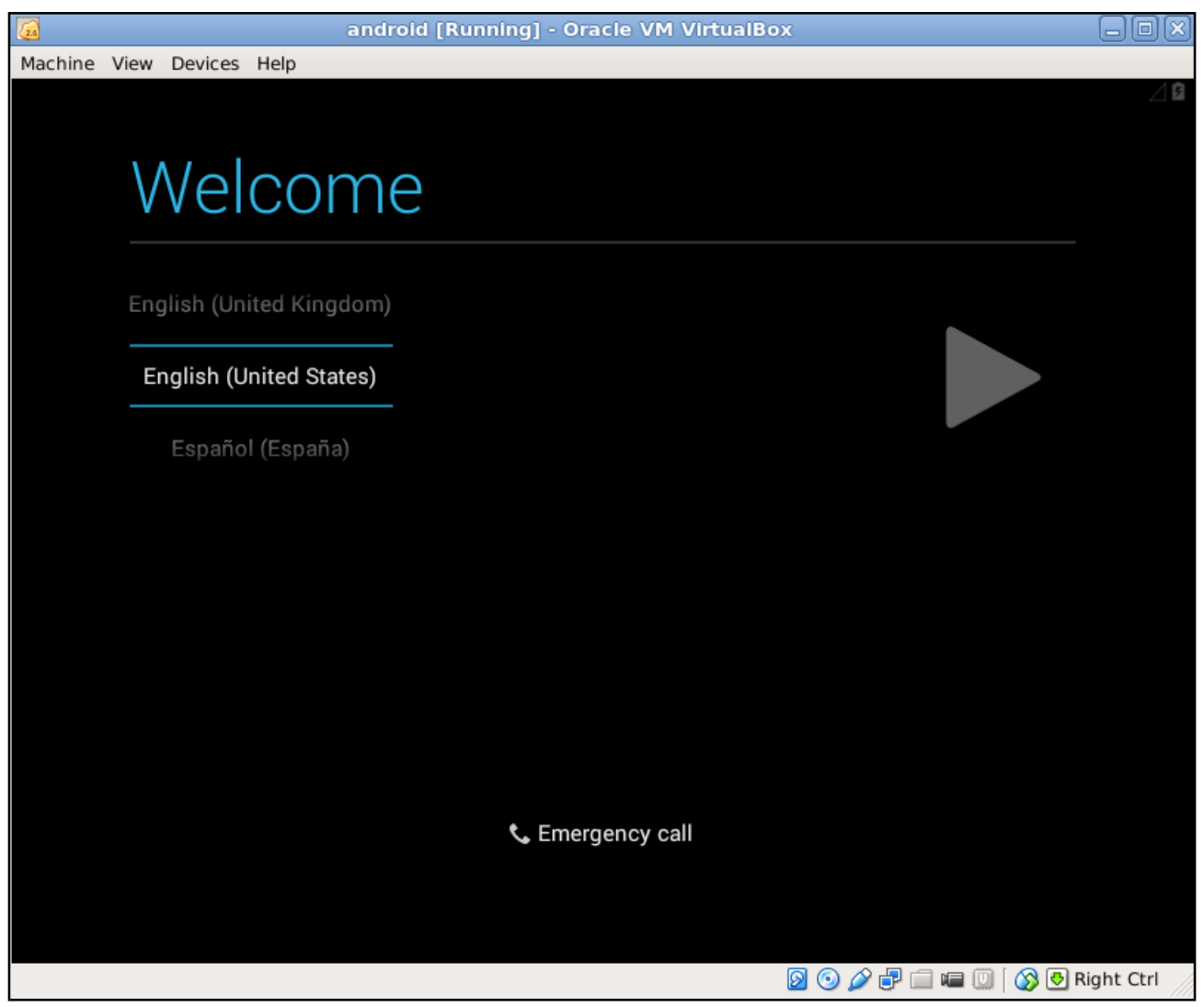

Fig. 24 Android welcome screen

25) After the Android on VM is successfully started, it needs to connect to the Linux host computer.

26) Setup the virtual box as a "Host-only Network" using the VirtualBox Preference Menu. Go to $<$ File- $>$ Preference- $>$ Network $>$, choose $<$ Host-only Networks $>$, and click the $<$ Add $>$ icon. Use the default name $<$ vboxnet $0>$.

27) Select the VM just created; click the $<$ Settings $>$ button, go to the $<$ Network $>$ setting. Under $<$ Adaptor $1>$ selection, pick the $<$ Attached to $>$ option to $<$ Host-only Adaptor $>$ and make sure the $<$ Name $>$ is set to $<$ vboxnet $0>$. Click the $<$ OK $>$ button.

28) Open a new terminal, and type the command $<$ ifconfig $>$ to list all possible connected network devices on the host computer.

29) Find the device with $<$ vboxnet $0>$, and use the same subnet for the new Android VM. For example, if the Internet Protocol (IP) address for $<$ vboxnet $0>$ is 192.168 .56 .1 , then use 192.168.56.101 as the IP address for the Android VM. 
30) Assuming that the Android SDK is installed correctly, type <adb start-server $>$ to start the Android-to-host-computer connection process.

31) Type $<\mathrm{adb}$ connect (ip of VM) $>$ to connect the VM-for example, $<$ adb connect 192.168.56.101>.

32) Type $<$ adb devices $>$ to determine whether the VM is actually connected.

33) If there is more than 1 device connected to the host computer, then type $<\mathrm{adb}-\mathrm{s}$ deviceip shell $>$ to connect the device you want to the host computer-for example, $<\mathrm{adb}-\mathrm{s}$ 192.168.56.101:5555>. You must type the full name of the device including port (as shown in the $<\mathrm{adb}$ devices $>$ command) to connect the device.

34) Type $<\mathrm{adb}$ devices $>$ to verify the devices are connected.

\section{Conclusions}

This step-by-step guide provides details on how to setup the VM running Android on an x86based processor. 


\section{References}

1. Oracle VirtualBox. [accessed 24 July 2014]. https://www.virtualbox.org/.

2. Android-x86 - Porting Android to x86. [accessed 24 July 2014]. http://www.android-x86.org/.

3. Android SDK. [accessed 24 July 2014]. http://developer.android.com/sdk/index.html. 


\section{List of Symbols, Abbreviations, and Acronyms}

GRUB GNU GRand Unified Bootloader

IP Internet Protocol

ISO International Organization for Standardization

SDK Software Development Kit

VDI Virtualbox Disk Image

VM Virtual Machine 
1 DEFENSE TECHNICAL

(PDF) INFORMATION CTR

DTIC OCA

2 DIRECTOR

(PDF) US ARMY RSRCH LAB

RDRL CIO LL

RDRL IMAL HRA RECORDS MGMT

1 DIRECTOR

(PDF) US ARMY RSRCH LAB

RDRL CIN D

K YU 